\title{
Interaction of Two-phase Debris Flow with Lateral Converging Shear Walls
}

\author{
Parameshwari Kattel ${ }^{1,2}$ and Bhadra Man Tuladhar ${ }^{1}$ \\ ${ }^{1}$ School of Science, Kathmandu University, Dhulikhel, Kavre, Nepal. \\ ${ }^{2}$ Department of Mathematics, Tri- Chandra Multiple Campus, Tribhuvan University, Kathmandu, Nepal \\ Correspondence to: Parameshwari Kattel, Email: pkattel@student.ku.edu.np
}

\begin{abstract}
Landslides, debris avalanches and debris flows are common mass wasting phenomena in mountain slopes. Debris flows can increase their volume and destructive potential by scouring undermining banks, thereby bringing morphological changes. Construction of lateral shear walls as embankments is a way of mitigation. In natural debris flows, solid and fluid evolve dynamically differently and show different interaction with obstacles. So, we employ a general two-phase mass flow model (Pudasaini, 2012) consisting of a set of highly non-linear and hyperbolic-parabolic PDEs for mass and momentum balances for both downslope and cross-slope directions. Besides buoyancy, the model includes the dominant physical aspects of the flow: virtual mass force, generalized drag and non-Newtonian viscous stress. Our numerical experiments show that the solid is more obstructed than the fluid when a debris flow passes over a system of converging lateral shear walls resulting in different flow-dynamics, wall-interactions and run out morphology of the phases. Narrower the slit, more is the obstruction. Solid component is more obstructed than the fluid, resulting in a phase-separation. The obstruction is related with the contraction ratio due to the converging shear walls. These computations and the observations increase our understanding of the flow dynamics and interactions with the lateral shear walls. The results may be extended further to achieve some engineering solutions to hazard mitigation in debris-flow prone zones.
\end{abstract}

Keywords: Debris flows, Two-phase mass flows, Converging lateral shear walls, Contraction ratio, Flow obstruction

\section{Introduction}

Landslides, debris flows, rock falls and flash floods are common gravitational mass movements, those occur in mountainous areas. A debris flow is the downslope movement of water saturated loose mass of sediments flow in response to gravity [15, 19, 34, 37. The debris flow triggering process may involve cloudburst, long period of rainfall, extensive snow- and ice-melt, and dam failure and lake outburst 43. A debris flow, generally has a huge momentum, significant energy and a much longer run out, resulting in more destructive power than other gravitational mass flows. This is due to the rapid motion, and especially the interactions between the mechanically strong solid material with water. A debris flow not only brings morphological changes in the inundation area, but also claims human lives and devastates civil structures 9, 14, 15, 23, 27, 29, 37, 38. Appropriate control and protective measures can reduce such losses 31.

The control measures of debris flow may be of active or passive types. Passive measures attempt to reduce the potential loss from avalanches, landslides and debris flow by land use planning, hazard zoning or by warning and evacuation. But, active mitigation measures attempt to decrease discharge and run off, decrease vertical and lateral erosion, and sometimes deflect and redirect the flow [3, 4, 5, 11, 13, 18, 31, 41. Debris flow protective measures may include engineering structures constructed in the flow path for diversion, retention, drainage or passing through purpose, mainly for controlling the water and sediments [11, 43. Structural defence structures are widely used countermeasures for controlling sediments and fluid in floods and debris flows. The structures may include single or multiple units like rigid and flexible barriers, levees, braking mounds, catching or deflecting dams, shear walls, spillways and baffles [11, 12, 40].

The lateral sides of a channelized debris flow are generally exposed to erosion. To retain the stability against the lateral erosion, construction of shear walls is a type of mitigation measure. Converging lateral shear walls provide additional effects of diverting the lateral energy of the debris flow downstream, along with the dosing, i.e., the temporary and partial retention of the sediments. By adjusting the location and the size of the opening of the constriction, a reliable hydraulic control can be achieved . This is a type of control to fix a relationship between the depth and discharge in its vicinity so as to reduce the excessive 
energy [11, 43]. Lateral shear walls are generally massive masonry structures made of concrete, rocks and steel because they have to withstand huge dynamic impact forces of the surging debris of a large, and highly mobile mass. The location, size and the strength of the defence structure depend upon the parameters of the debris flow, e.g., the slope and slope orientation, topography, anticipated volume of the debris flows, their type and velocity, and the nature of the object or the area to be protected [7, 18, 31. The dynamic response of masonry structures for the solid and fluid phases of a debris flow largely depend upon the parameters of the debris flow and the masonry structure itself (height, length, width and slope) 26.

Debris flows evolve in a complicated manner. So, a single rheological equation may not be sufficient enough to describe them. Various rheological models were proposed in the past being based on single-phase models, e.g., viscoplastic continuum or Bingham model [15, 19, 37. Iverson [15, Iverson and Denlinger, [16] and Pudasaini et al. 34] treated debris flows as effectively a single-phase model, Pitman and Le 27] proposed two-fluid model whereas Fernandez-Nieto et al. 9] considered two-layered model for the study of debris flows. Pudasaini [29] proposed a comprehensive theory and simulation technique [30, 32] that turned out to be a major advancement in modelling and simulation of two-phase debris flow. The model includes buoyancy and strong interactions between the phases. Three other dominant physical aspects of flow: enhanced non-Newtonian viscous stress induced by gradient of solid volume fraction, virtual mass force and generalized drag were also incorporated in the model. So, we use this general model to simulate the interaction of two-phase debris flow with lateral shear walls.

Being based on the general two-phase mass flow model of Pudasaini 29] and the simulation techniques, various simulations of two-phase debris flows in geometrically three-dimensional generic subaerial slope [21, 23], and submarine debris flows [20, 30] have been carried out. Mergili et al. 24] presented more simulations for real mountain topographies. Obstacle interactions are also found to be discussed for granular flows [10, 31, 35, 42], or for a debris bulk without considering two separate phases [5, 28, 44]. The evolution and the dynamic behaviour of the solid- and the fluid-phases in natural debris flows are different [27, 29]. Due to different material properties and rheologies, the phases may interact with the obstacles differently 22. However, almost all the studies related with debris flow past obstacles concern single-phase debris flows [5, 8]. Kattel et al. [22] analyzed in details of the separate phase and the combined interaction of debris mixture with tetrahedral obstacles of different orientation, spacing and numbers to study the geometric contributions to phase-separation and compute the dynamic impact pressure. Our present study focuses on the separate interactions of two-phase debris flows with obstacles providing lateral confinements to the flow. As an example of a shear wall in the debris flow path, Fig. 1 is a photograph of a $9 \mathrm{~m}$ long

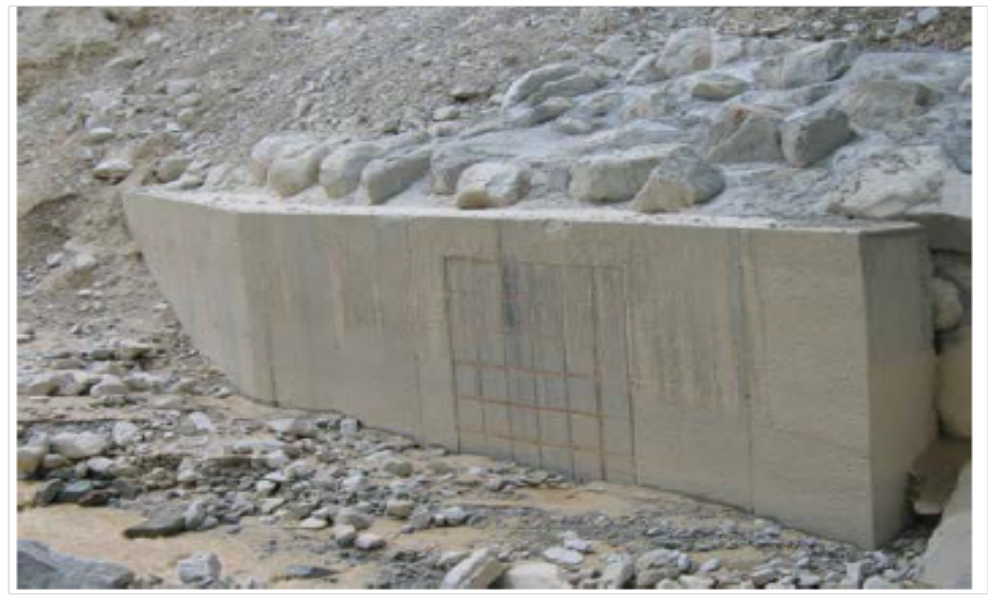

Figure 1: Shear wall in the Illgraben debris flow, Switzerland (Source: Wendeler, 2016 [4])

shear wall aligned at $20^{\circ}$ to the flow followed by the flow-parallel part of the wall. The three rows of six geophones installed on the surface provide information on the velocity profile and the forces of a debris flow when it passes along it. 
Although dynamical aspects including the momentum loss, energy dissipation, and energy transfer from the lateral to longitudinal directions are very important quantitative aspects of study in the interaction of the flow with lateral converging shear walls, here, we especially focus on the geometrical aspects of interactions, mainly the evolution of solid and fluid flow depths in the vicinity of the walls, the deflections, and the obstruction of the solid phase due to different contractions. The key objective of the study is to characterize the effects of obstruction of the debris mass due to the interaction with the converging lateral walls and the contraction in the flow in order to add on information on risk mitigation.

\section{The Model Equations}

We consider the general two phase mass flow model [29] that can describe evolutions, dynamics and different interactions of solid and fluid phases, and the debris bulk as a whole with obstacles. In a two-phase debris flow model, for the solid phase, its material density $\rho_{s}$, internal friction angle $\phi$, basal friction angle $\delta$, an anisotropic stress distribution, and the lateral earth pressure coefficients $K_{x}$ and $K_{y}$ are important; whereas for the fluid phase, material density $\rho_{f}$, viscosity $\eta_{f}$ and an isotropic stress distribution are included to characterize it. The subscripts $s$ and $f$ denote the solid and fluid phases, respectively. The model integration computes the flow depth $h$, volume fraction of the solid $\alpha_{s}$ (or the fluid $\alpha_{f}=1-\alpha_{s}$ ), the depth-averaged velocity components for fluid $\mathbf{u}_{f}=\left(u_{f}, v_{f}\right)$ and for solid $\mathbf{u}_{s}=\left(u_{s}, v_{s}\right)$ in the downslope and the cross-slope directions respectively. The model employed for the simulations consists of the following mass (1)-(2), and momentum balances for solid (3)-(4) and fluid (5)-(6) in the $x$ - and $y$-directions respectively [29].

$$
\begin{aligned}
& \frac{\partial}{\partial t}\left(\alpha_{s} h\right)+\frac{\partial}{\partial x}\left(\alpha_{s} h u_{s}\right)+\frac{\partial}{\partial y}\left(\alpha_{s} h v_{s}\right)=0, \\
& \frac{\partial}{\partial t}\left(\alpha_{f} h\right)+\frac{\partial}{\partial x}\left(\alpha_{f} h u_{f}\right)+\frac{\partial}{\partial y}\left(\alpha_{f} h v_{f}\right)=0 \\
& \frac{\partial}{\partial t}\left[\alpha_{s} h\left(u_{s}-\gamma \mathcal{C}\left(u_{f}-u_{s}\right)\right)\right]+\frac{\partial}{\partial x}\left[\alpha_{s} h\left(u_{s}^{2}-\gamma \mathcal{C}\left(u_{f}^{2}-u_{s}^{2}\right)+\frac{\beta_{x_{s}} h}{2}\right)\right] \\
& +\frac{\partial}{\partial y}\left[\alpha_{s} h\left(u_{s} v_{s}-\gamma \mathcal{C}\left(u_{f} v_{f}-u_{s} v_{s}\right)\right)\right]=h S_{x_{s}}, \\
& \frac{\partial}{\partial t}\left[\alpha_{s} h\left(v_{s}-\gamma \mathcal{C}\left(v_{f}-v_{s}\right)\right)\right]+\frac{\partial}{\partial x}\left[\alpha_{s} h\left(u_{s} v_{s}-\gamma \mathcal{C}\left(u_{f} v_{f}-u_{s} v_{s}\right)\right)\right] \\
& +\frac{\partial}{\partial y}\left[\alpha_{s} h\left(v_{s}^{2}-\gamma \mathcal{C}\left(v_{f}^{2}-v_{s}^{2}\right)+\frac{\beta_{y_{s}} h}{2}\right)\right]=h S_{y_{s}} \\
& \frac{\partial}{\partial t}\left[\alpha_{f} h\left(u_{f}+\frac{\alpha_{s}}{\alpha_{f}} \mathcal{C}\left(u_{f}-u_{s}\right)\right)\right]+\frac{\partial}{\partial x}\left[\alpha_{f} h\left(u_{f}^{2}+\frac{\alpha_{s}}{\alpha_{f}} \mathcal{C}\left(u_{f}^{2}-u_{s}^{2}\right)+\frac{\beta_{x_{f}} h}{2}\right)\right] \\
& +\frac{\partial}{\partial y}\left[\alpha_{f} h\left(u_{f} v_{f}+\frac{\alpha_{s}}{\alpha_{f}} \mathcal{C}\left(u_{f} v_{f}-u_{s} v_{s}\right)\right)\right]=h S_{x_{f}} \\
& \frac{\partial}{\partial t}\left[\alpha_{f} h\left(v_{f}+\frac{\alpha_{s}}{\alpha_{f}} \mathcal{C}\left(v_{f}-v_{s}\right)\right)\right]+\frac{\partial}{\partial x}\left[\alpha_{f} h\left(u_{f} v_{f}+\frac{\alpha_{s}}{\alpha_{f}} \mathcal{C}\left(u_{f} v_{f}-u_{s} v_{s}\right)\right)\right] \\
& +\frac{\partial}{\partial y}\left[\alpha_{f} h\left(v_{f}^{2}+\frac{\alpha_{s}}{\alpha_{f}} \mathcal{C}\left(v_{f}^{2}-v_{s}^{2}\right)+\frac{\beta_{y_{f}} h}{2}\right)\right]=h S_{y_{f}}
\end{aligned}
$$


where the pressures are given by

$$
\beta_{x_{s}}=\varepsilon K_{x} p_{b_{s}}, \beta_{y_{s}}=\varepsilon K_{y} p_{b_{s}}, \beta_{x_{f}}=\beta_{y_{f}}=\varepsilon p_{b_{f}}, p_{b_{f}}=-g^{z}, p_{b_{s}}=(1-\gamma) p_{b_{f}}
$$

The source terms are (Pudasaini, 2012):

$$
\begin{aligned}
& S_{x_{s}}=\alpha_{s}\left[g^{x}-p_{b_{s}}\left(\frac{u_{s}}{\left|\mathbf{u}_{\mathbf{s}}\right|} \tan \delta+\varepsilon \frac{\partial b}{\partial x}\right)\right]-\varepsilon \alpha_{s} \gamma p_{b_{f}}\left[\frac{\partial h}{\partial x}+\frac{\partial b}{\partial x}\right] \\
& +C_{D G}\left(u_{f}-u_{s}\right)\left|\mathbf{u}_{f}-\mathbf{u}_{s}\right|^{J-1}, \\
& S_{y_{s}}=\alpha_{s}\left[g^{y}-p_{b_{s}}\left(\frac{v_{s}}{\left|\mathbf{u}_{\mathbf{s}}\right|} \tan \delta+\varepsilon \frac{\partial b}{\partial y}\right)\right]-\varepsilon \alpha_{s} \gamma p_{b_{f}}\left[\frac{\partial h}{\partial y}+\frac{\partial b}{\partial y}\right] \\
& +C_{D G}\left(v_{f}-v_{s}\right)\left|\mathbf{u}_{f}-\mathbf{u}_{s}\right|^{J-1}, \\
& S_{x_{f}}=\alpha_{f}\left[g^{x}-\varepsilon\left[\frac{1}{2} p_{b_{f}} \frac{h}{\alpha_{f}} \frac{\partial \alpha_{s}}{\partial x}+p_{b_{f}} \frac{\partial b}{\partial x}-\frac{1}{\alpha_{f} N_{R}}\left\{2 \frac{\partial^{2} u_{f}}{\partial x^{2}}+\frac{\partial^{2} v_{f}}{\partial y \partial x}+\frac{\partial^{2} u_{f}}{\partial y^{2}}-\frac{\chi u_{f}}{\varepsilon^{2} h^{2}}\right\}\right.\right. \\
& +\frac{1}{\alpha_{f} N_{R_{\mathcal{A}}}}\left\{2 \frac{\partial}{\partial x}\left(\frac{\partial \alpha_{s}}{\partial x}\left(u_{f}-u_{s}\right)\right)+\frac{\partial}{\partial y}\left(\frac{\partial \alpha_{s}}{\partial x}\left(v_{f}-v_{s}\right)+\frac{\partial \alpha_{s}}{\partial y}\left(u_{f}-u_{s}\right)\right)\right\} \\
& \left.\left.-\frac{\xi \alpha_{s}\left(u_{f}-u_{s}\right)}{\varepsilon^{2} \alpha_{f} N_{R_{\mathcal{A}}} h^{2}}\right]\right]-\frac{1}{\gamma} C_{D G}\left(u_{f}-u_{s}\right)\left|\mathbf{u}_{f}-\mathbf{u}_{s}\right|^{J-1}, \\
& S_{y_{f}}=\alpha_{f}\left[g^{y}-\varepsilon\left[\frac{1}{2} p_{b_{f}} \frac{h}{\alpha_{f}} \frac{\partial \alpha_{s}}{\partial y}+p_{b_{f}} \frac{\partial b}{\partial y}-\frac{1}{\alpha_{f} N_{R}}\left\{2 \frac{\partial^{2} v_{f}}{\partial y^{2}}+\frac{\partial^{2} u_{f}}{\partial x \partial y}+\frac{\partial^{2} v_{f}}{\partial x^{2}}-\frac{\chi v_{f}}{\varepsilon^{2} h^{2}}\right\}\right.\right. \\
& +\frac{1}{\alpha_{f} N_{R_{\mathcal{A}}}}\left\{2 \frac{\partial}{\partial y}\left(\frac{\partial \alpha_{s}}{\partial y}\left(v_{f}-v_{s}\right)\right)+\frac{\partial}{\partial x}\left(\frac{\partial \alpha_{s}}{\partial y}\left(u_{f}-u_{s}\right)+\frac{\partial \alpha_{s}}{\partial x}\left(v_{f}-v_{s}\right)\right)\right\} \\
& \left.\left.-\frac{\xi \alpha_{s}\left(v_{f}-v_{s}\right)}{\varepsilon^{2} \alpha_{f} N_{R_{\mathcal{A}}} h^{2}}\right]\right]-\frac{1}{\gamma} C_{D G}\left(v_{f}-v_{s}\right)\left|\mathbf{u}_{f}-\mathbf{u}_{s}\right|^{J-1},
\end{aligned}
$$

where the parameters are

$$
\begin{aligned}
& C_{D G}=\frac{\alpha_{s} \alpha_{f}(1-\gamma)}{\left[\varepsilon \mathcal{U}_{T}\left\{\mathcal{P F}\left(R e_{p}\right)+(1-\mathcal{P}) \mathcal{G}\left(R e_{p}\right)\right\}\right]^{J}}, \gamma=\frac{\rho_{f}}{\rho_{s}}, \mathcal{F}=\frac{\gamma}{180}\left(\frac{\alpha_{f}}{\alpha_{s}}\right)^{3} R e_{p}, \\
& \mathcal{G}=\alpha_{f}^{M\left(R e_{p}\right)-1}, R e_{p}=\frac{\rho_{f} d \mathcal{U}_{T}}{\eta_{f}}, N_{R}=\frac{\sqrt{g L} H \rho_{f}}{\alpha_{f} \eta_{f}}, N_{R_{\mathcal{A}}}=\frac{\sqrt{g L} H \rho_{f}}{\mathcal{A} \eta_{f}}
\end{aligned}
$$

In (1)-11), $x, y$ and $z$ refer to the coordinates along the downslope, the cross-slope and the direction perpendicular to the flow surface respectively, and $g^{x}, g^{y}$ and $g^{z}$ are the respective components of acceleration due to gravity. $\varepsilon=H / L$ is the aspect ratio of the typical extent to the depth of the flow. $\mu=\tan \delta$ is the basal friction coefficient. $C_{D G}$ is the generalized drag coefficient; $J=1$ or 2 represents linear (laminar-type) or quadratic (turbulent-type) drag. $\mathcal{U}_{T}$ is the terminal velocity of a particle. $\mathcal{P}$, which takes values within 0 and 1 , is an interpolation parameter to combine the solid-like $(\mathcal{G})$ and fluid-like $(\mathcal{F})$ drag contributions to flow resistance. $p_{b_{f}}$ and $p_{b_{s}}$ are the effective fluid and solid pressures. $\gamma$ is the ratio of the density of the fluid phase to that of the solid phase, $\mathcal{C}$ is the virtual mass coefficient, $M$ is a function of the particle Reynolds number $\left(R_{e_{p}}\right), \chi$ includes vertical shearing of fluid velocity, and $\xi$ takes into account different distributions of $\alpha_{s} . \mathcal{A}=\mathcal{A}\left(\alpha_{f}\right)$ is the mobility of the fluid at the interface. $N_{R}$ is a quasi-Reynolds number, and $N_{R_{\mathcal{A}}}$, a mobility-Reynolds number associated with the classical Newtonian and enhanced non-Newtonian fluid viscous stresses respectively. The basal and obstacle topography $z=b(x, y)$, along with the aforementioned material parameters, and initial and boundary conditions (see, Section 3 ) are given as model inputs so that 
the equations (1)-(6) yield the outputs as debris flow depth $h$, volume fraction of the fluid $\alpha_{f}$ (or solid $\left.\alpha_{s}\right)$ or equivalently, solid- and fluid-phase depths $\left(h_{s}=\alpha_{s} h, h_{f}=\alpha_{f} h\right)$ and the depth-averaged velocity components for solid $u_{s}$ and $v_{s}$, and for fluid $u_{f}$ and $v_{f}$ in the downslope and the cross-slope directions respectively, as functions of space and time. Mohr-Coulomb plastic rheology for the solid and enhanced non-Newtonian viscous rheology for the fluid are employed in the model.

\section{Simulation Set-up}

\subsection{Topography, Initial Debris and Lateral Walls}

The topography is in the form of a slope surface in the downslope direction from $x=x_{0}=-50 \mathrm{~m}$ to $x=x_{r}=150 \mathrm{~m}$, inclined at an angle $\zeta_{0}=45^{\circ}$, that follows a horizontal run out zone to $x=x_{f}=450$ $\mathrm{m}$. The cross-slope domain ranges from $y=-200 \mathrm{~m}$ to $y=200 \mathrm{~m}$ as shown in Fig. 2. In the flow, the obstruction and the redirection are given by two converging lateral shear walls in gray at $[50, \pm 100]$ $\mathrm{m} \times[100, \pm \tilde{y}] \mathrm{m}$, where $\tilde{y}$ varies to give different contractions and convergences to the flow. The initial

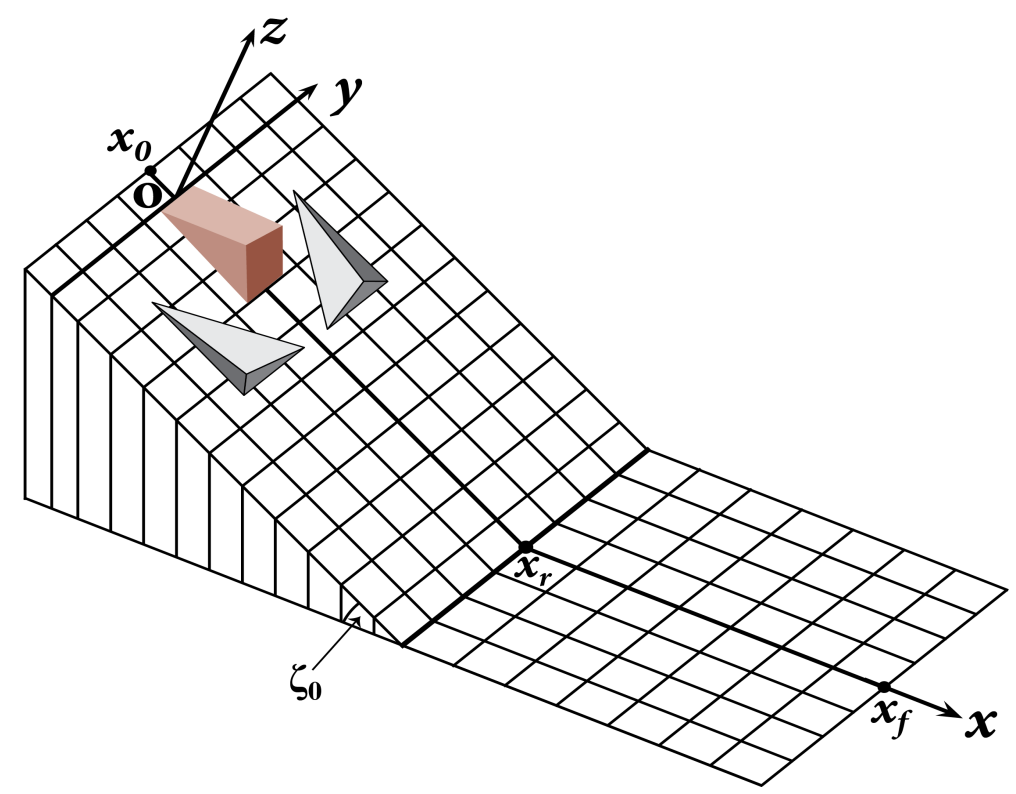

Figure 2: Initial set up for the simulation of debris flow past lateral converging shear walls

deformable debris mass in brown is kept as a triangular wedge $0 \mathrm{~m} \leq x \leq 50 \mathrm{~m},-15 \mathrm{~m} \leq y \leq 15 \mathrm{~m}$ that contains a homogeneous mixture of solid (75\%) and fluid (25\%). Simulations are carried out by releasing the debris mass that flows down a channel interacting with the non-deformable converging lateral walls so that the guided flow reaches the horizontal run-out zone. The flow obstruction due to lateral walls are implemented in the model by the local height changes in the basal topography [29, 42. As the flow impacts and interacts with the walls, the gradients of the walls $(\partial b / \partial x, \partial b / \partial y)$ act as redirecting force, which transfers the lateral momentum of the flow towards downstream, during the interaction.

\subsection{Parameter Choice and Numerical Method}

The common non-dimensional parameters chosen for the simulation results presented here are: $\phi=35^{\circ}$, $\delta=15^{\circ}, \mathcal{U}_{T}=1.0, R e_{p}=1, \chi=3, \xi=5, \mathcal{P}=0.45, J=1, \mathcal{C}=0.4, \quad N_{R}=30,000$, and $N_{R_{\mathcal{A}}}=1,000$. The solid and fluid densities are $\rho_{s}=2800 \mathrm{Kg} / \mathrm{m}^{3}$ and $\rho_{f}=1100 \mathrm{Kg} / \mathrm{m}^{3}$, respectively. Gravitational mass flows may possess large deformations and abrupt changes in flow dynamical variables due to the rapid motion and potential interaction with obstacles. Here, we capture such complicated evolving and 
interacting behaviour of debris flow by employing high-resolution Total Variation Diminishing (TVD) NonOscillatory Central (NOC) schemes to numerically integrate the model equations (1)-(6). The methods are efficient even if shocks are produced [17, 24, 25, 31, 36].

\section{Simulation Results and Discussions}

In the following, we describe the evolution of solid- and fluid-phases and the total debris bulk when the initial debris mixture is released and flows down the slope. When the flowing debris mass encounters converging lateral walls of different outlet width, we especially focus on the flow-obstacle-interaction. Here, we do not present the reference simulation, when the flow is undisturbed. The details can be found in Kattel et al. 22.

\subsection{Bilateral Contraction with Outlet Width of $32 \mathrm{~m}$}

In this numerical experiment (Fig. 33), the debris flow encounters a set of two converging lateral solid walls that gives a moderate bilateral contraction to the flow. When the debris mass is released at $t=0 \mathrm{~s}$, it advects (moves downslope) and disperses (spreads cross-slope). The flowing mass begins to interact with the walls at $t=2 \mathrm{~s}$. At $t=3 \mathrm{~s}$, the debris front begins to exit out of the opening. At $t=5 \mathrm{~s}$, due to the lateral obstruction in the flow, the maxima of solid, fluid and the total debris mixture are found to be localized in the vicinity of the walls. Since the walls are high enough $(H=25 \mathrm{~m})$, the flow cannot overrun the top of the walls. Due to topographic gradients and pressure, a large portion of the elevated mass descends down; more mass exits out $(t=7 \mathrm{~s})$. As the walls obstruct more solid than fluid, more fluid mass exits out. At $t=9 \mathrm{~s}$, the exited fluid mass moves more downslope and disperses more cross-slope than solid. Even at $t=11 \mathrm{~s}$, a considerable amount of solid mass is still observed in the vicinity of the walls, whereas the entire fluid already exits out of the walls. The main fluid body is wider and less elongated than the solid body. Solid and fluid, thus, show different flow dynamics, and obstacle-interactions. As almost all the fluid mass exits out of the walls and has shown the run out morphology, we stop the simulation at $t=11 \mathrm{~s}$.

The converging lateral walls and the outlet opening together give a funneling effect to the flow. Flowing debris mass on passing through the gate is found to be contracted. The maximum contraction takes place at a section, called vena contracta, just downstream of the gate. It is also the section, where the velocity of the flowing debris mass attains its maximum, beyond which the flow decelerates and diverges, showing run out morphology [6]. At $t=9 \mathrm{~s}$, the vena contracta for fluid is much wider than that for solid.

\subsection{Bilateral Contraction with Outlet Width of $2 \mathrm{~m}$}

Next, we present the other numerical experiment in Fig. 4 , where the lateral walls give more convergence to the flow with the outlet opening of width $2 \mathrm{~m}$. Until $t=3 \mathrm{~s}$, the flow evolutions for solid, fluid and the total debris mass are similar to those in Fig. 3 From $t=3 \mathrm{~s}$, more obstruction in the flow is observed. From $t=3 \mathrm{~s}$ to $t=5 \mathrm{~s}$, the depth of the solid, fluid and the total debris bulk are increased in the vicinity of the lateral walls as the walls momentarily hold maximum of the debris material, providing more obstruction to the flow. This results in more elevation of the debris mass on the walls than in Fig. 3, and the dosing is more pronounced. As the pressure is developed due to accumulation and the elevating momentum is ceased, the walls can not hold the debris mass further. After $t=5 \mathrm{~s}$, when more debris material exit out of the opening, the depth slowly begins to decrease. At $t=7 \mathrm{~s}$, the relative maxima for solid, fluid and total debris bulk lie in the vicinity of the walls. The substantial holding of solid mass by the walls continues even until $t=11 \mathrm{~s}$, but the relative maximum for fluid lies in the run out zone. This shows a substantial phase-separation in the debris flow [33] due to the topographic gradients and the narrower outlet due to the walls. On observing the panels for $t=11 \mathrm{~s}$, due to this phase-separation, the debris body consists of mechanically weaker fluid-rich debris head in the run out zone, which is followed by mechanically stronger solid-rich tail entrapped in the vicinity of the walls. Changing geometry of debris tail is due to the narrower outlet opening. The more obstruction due to the narrower outlet is intuitively clear. Something which is counter intuitive is the run out distance, which should have substantially shortened due to this obstruction. However, more pressurized release of the flow counterbalances the expected shortening in run out distance. 


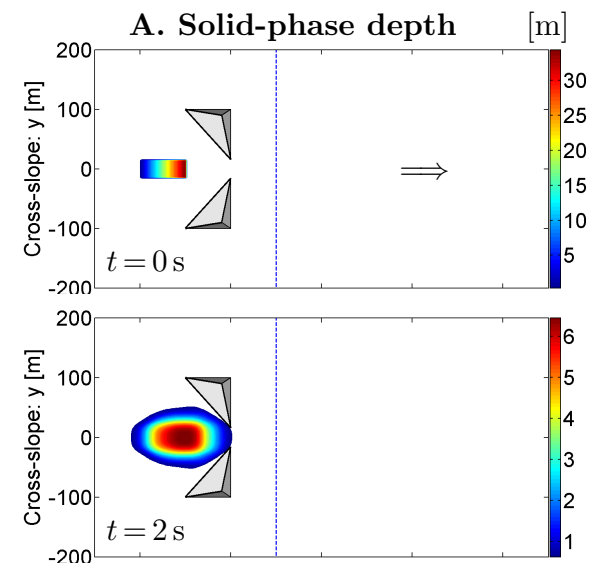

B. Fluid-phase depth
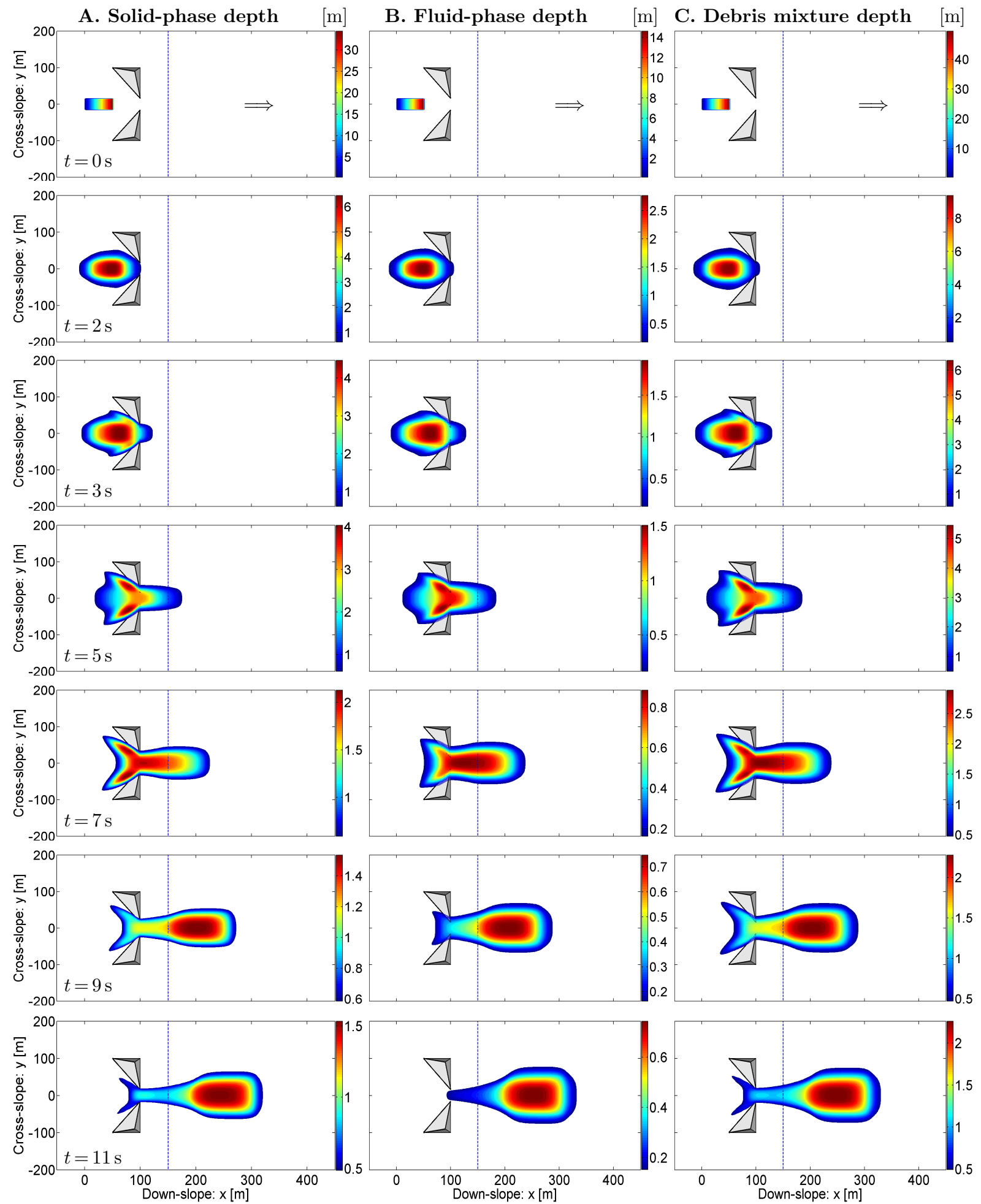

Figure 3: Bilateral contraction with outlet width of $32 \mathrm{~m}$ : Evolution of A. Solid phase, B. Fluid phase, C. Total debris mixture and the interaction with lateral shear walls as an initial homogeneous debris mixture of solid and fluid is released and moves downslope. Due to the obstruction, a part of the debris mass elevates the wall and descends down, producing oblique shocks. More solid is obstructed than fluid. The arrows in the top panels indicate the flow direction. The blue dashed line in each panel indicates the transition from the inclined plane to the horizontal run out. 


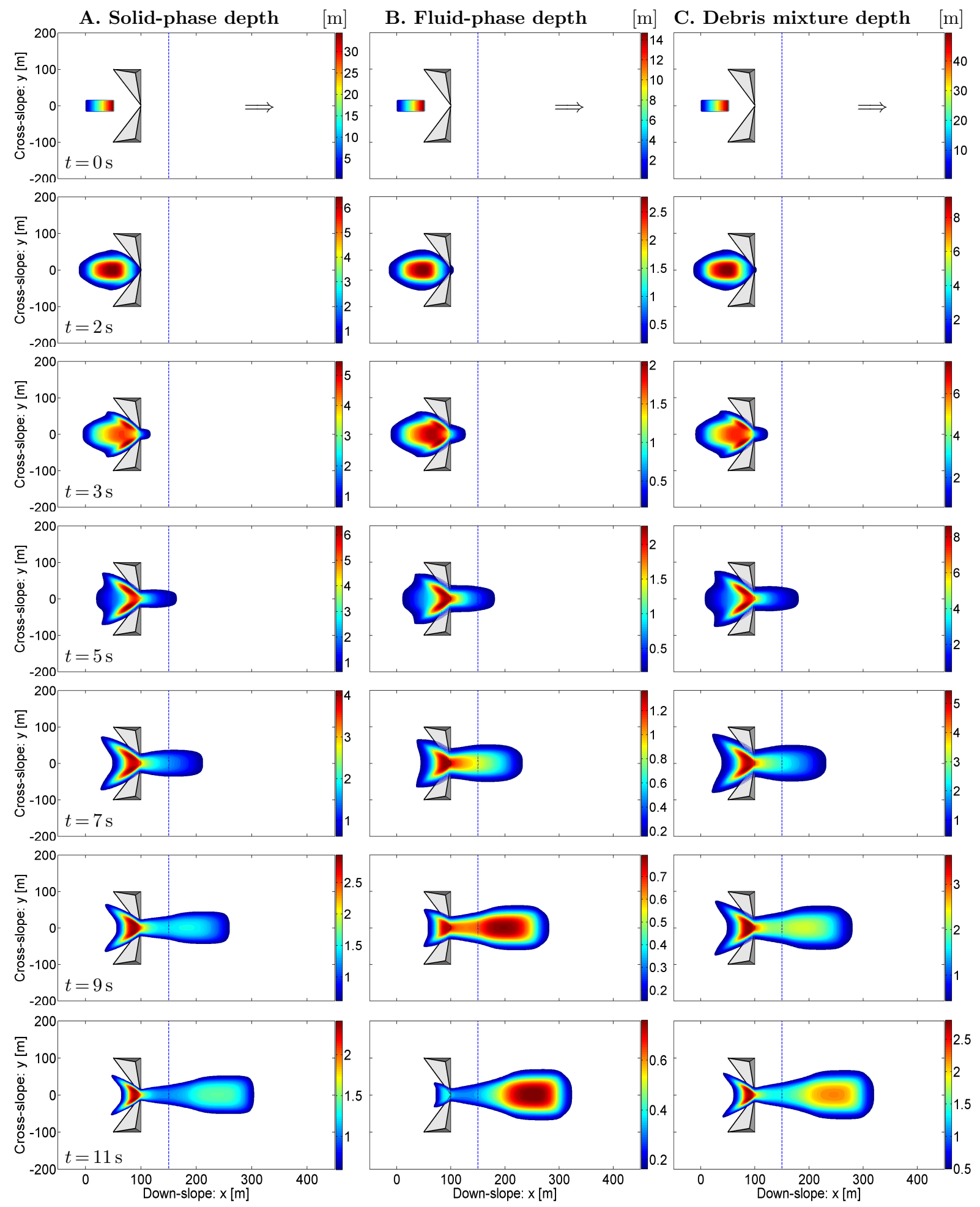

Figure 4: Bilateral contraction with outlet width of $2 \mathrm{~m}$ : Evolution of A. Solid phase, B. Fluid phase, $\mathbf{C}$. Total debris mixture and the interaction with lateral shear walls as an initial homogeneous debris mixture of solid and fluid is released and moves down a slope. Due to the narrower converging outlet, the debris mixture is more elevated and obstructed than in Fig. 3. Solid obstruction is more than the fluid. The arrows in the top panels indicate the flow direction. The blue dashed line in each panel indicates the transition from the inclined plane to the horizontal run out. 
Interaction of Two-phase Debris Flow with Lateral Converging Shear Walls
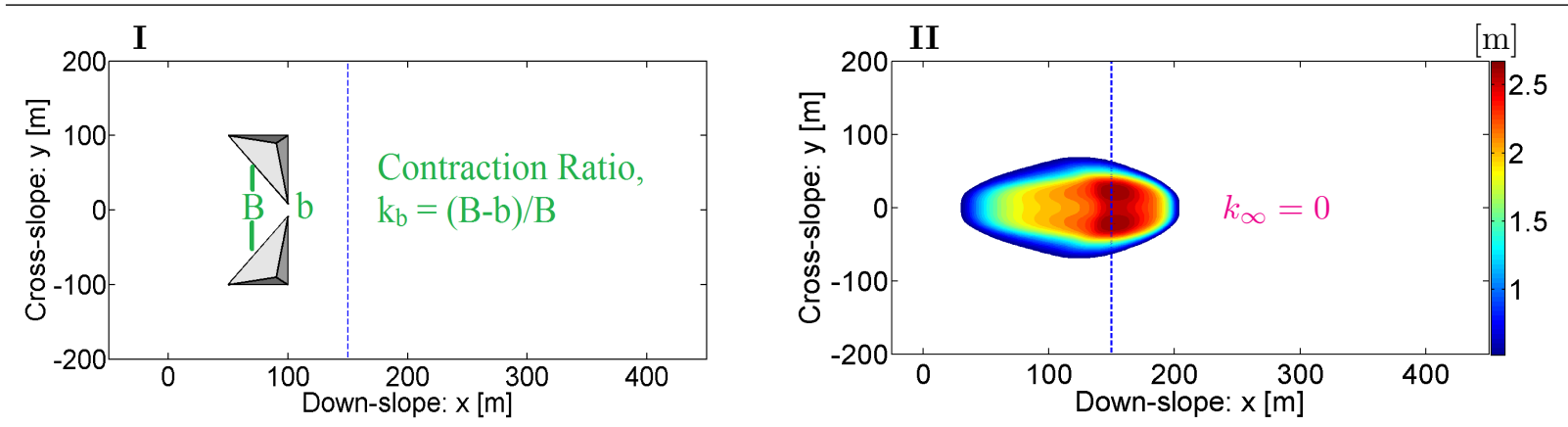

Figure 5: I: Inlet and outlet openings, and contraction ratio. II: Evolution of solid-phase for undisturbed flow at $t=5 \mathrm{~s}$

In Fig. 3 and Fig. 4, we observed that such converging lateral walls provide the obstruction in the flow by holding the flowing mass. The obstruction is more pronounced when the outlet width decreases. Moreover, the walls provide more obstruction to the solid component of the debris material than the fluid component. So, in the next section, we study the relation of solid obstruction with different contraction ratios.

\subsection{Obstruction of the Solid Component and Contraction Ratio}

In the previous two sections, we presented the flow evolutions and the flow-interactions (mainly, the obstructions) with lateral walls. The solid obstruction is more pronounced than the fluid and the maximum obstruction is observed at $t=5 \mathrm{~s}$. So, in what follows, we study the relation between the solid-phase obstruction with the different outlet opening widths (b). The effective inlet opening width is $B=48 \mathrm{~m}$ for all the wall arrangements, which we consider only when the debris mass just begins to interact with the walls. For the undisturbed flow, we assume $b=B$. We consider other cases when the outlet opening
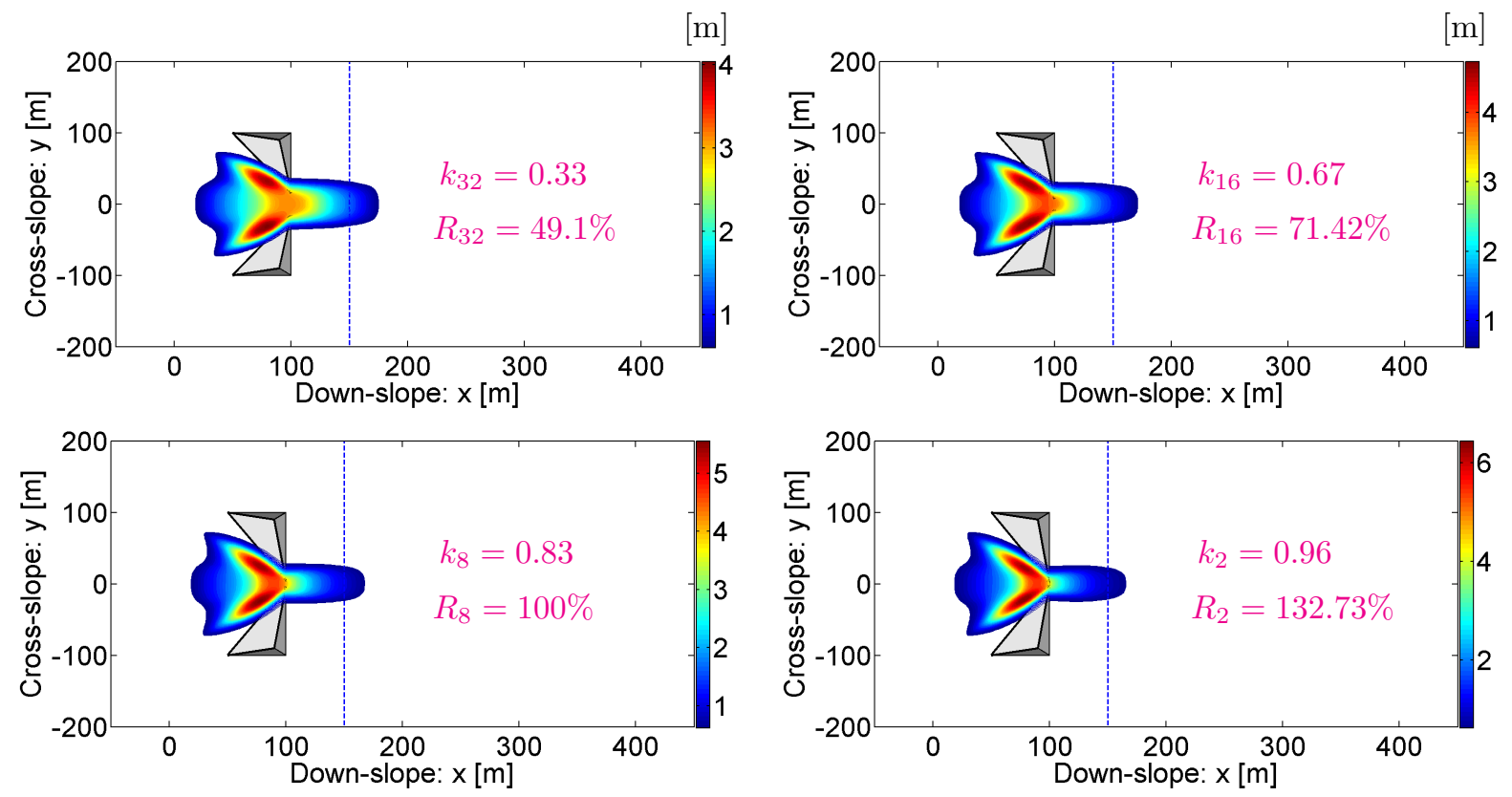

Figure 6: Interaction of solid phase with the lateral walls with different outlet widths, $b=32,16,8,2 \mathrm{~m}$ at $t=5 \mathrm{~s}$. 
widths are $b=32,16,8$ and $2 \mathrm{~m}$. Then, the contraction ratio for the outlet width $b$ is given by [1, 2]

$$
k_{b}=\frac{B-b}{B} .
$$

Then, the contraction ratio for the undisturbed flow (Fig. 5. II) is $k_{\infty}=0$.

Figure 6 presents the solid phase flow-wall-interaction at $t=5 \mathrm{~s}$ for the different outlet openings $(b=$ $32,16,8,2 \mathrm{~m})$. So, the respective contraction ratios by using (12) are $k_{32}=0.33, k_{16}=0.67, k_{8}=0.83$ and $k_{2}=0.96$. The colour bars given alongside of each panel show that the solid phase depths increase alongwith the increasing contraction ratios (i.e., decreasing outlet opening widths). This means that the obstruction of the solid components of the debris flows due to the walls depends upon the contraction ratio of the flow due to the outlet openings. We propose that the relative obstruction (in \%) of the solid component in the debris flow is given by

$$
R_{b}=\frac{h_{s_{b}}-h_{s_{\infty}}}{h_{s_{\infty}}} \times 100 \%,
$$

where $h_{s_{b}}$ is the maximum solid phase depth with the outlet opening width $b$, and $h_{s_{\infty}}$ is that for the undisturbed flow at the same instant of time. Using (13), the respective obstructions are found to be $R_{\infty}=0 \%, R_{32}=49.1 \%, R_{16}=71.42 \%, R_{8}=100 \%$, and $R_{2}=132.73 \%$. Figure 7 plots the relative obstruction of the solid component of the debris material versus the contraction ratio. It shows that the obstruction increases along with the increasing contraction ratio, and more rapidly for higher contraction ratios.

Here, we mainly focused on the contractions to the flow as given by converging lateral walls in the flow path, and presented a graphical relation between the obstruction of the solid component and the contraction ratios. Similar relation for fluid-phase obstruction and the total debris mixture obstruction can be computed. This is the advantage of the two-phase mass flow model and the simulation techniques as employed here. To derive an empirical relation in this context, more numerical experiments with varied geometrical and material settings are to be performed and are to be tested with laboratory experiments, which is not within the scope here.

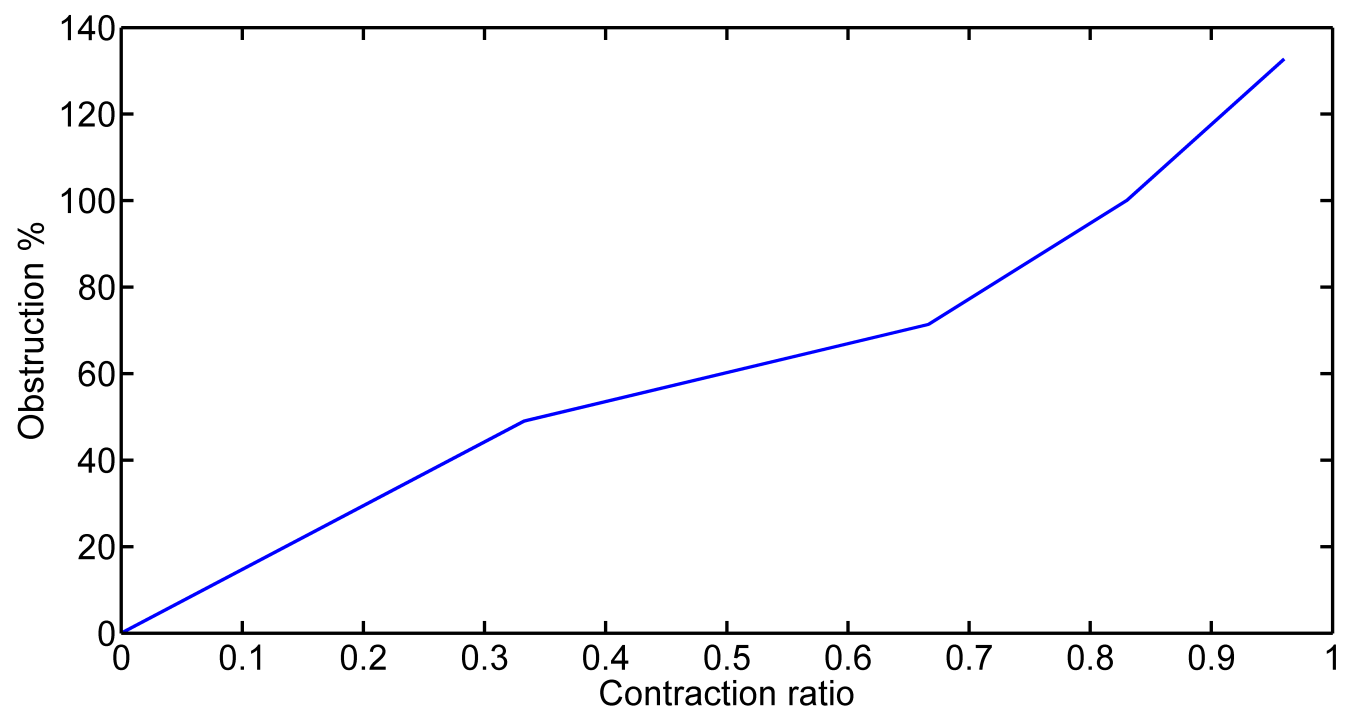

Figure 7: Relation between the relative obstruction of the solid component and the contraction ratio. 
Interaction of Two-phase Debris Flow with Lateral Converging Shear Walls

\section{Conclusions}

Here, we presented and discussed a couple of basic simulation results for two-phase mass flows on a generic topography, interacting with lateral converging walls with different outlet openings. Through the numerical experiments, we observed fundamentally different interacting behaviours and degree of obstructions of the solid and fluid components with non-deformable lateral walls. To the inlet openings of same width, contraction ratios for the flow increase with narrowing outlet openings. The obstruction in the flow increases with the increasing contraction ratios. The two-phase flow out of the narrower exits result in significant phase separation. As the debris head significantly loses solid material, the flow becomes less hazardous. Our results can be extended to use in hazard mitigation strategies in debris flow-, and GLOF (glacial lake outburst flood)-prone areas in mountains and valleys, especially to redirect flows from higher to lower vulnerable areas.

Acknowledgements: Parameshwari Kattel acknowledges University Grants Commission (UGC), Nepal for the financial support provided as a PhD fellowship (PhD-2071/072-Sci. \& Tech.-03).

\section{References}

[1] Chen H, Liu J, Zhao W (2016) Effects of Y-type spillway lateral contraction ratios on debris-flow patterns and scour features downriver of a check dam. Nat. Hazard. Earth Syst. Sci., 16, 2433-2442

[2] Choi SK, Lee JM, Kwon TH (2017) Effect of slit-type barrier on characteristics of water-dominant debris flows: Small scale physical modeling. Landslides (doi: 10.1007/s10346-017-0853-4)

[3] Choiu MC (2005) Modelling Dry Granular Avalanches Past Different Obstructs: Numerical Simulation and Laboratory Analyses. PhD Thesis, Technical University Darmstadt, Germany

[4] Chou SH, Lu LS and Hsaiau SS (2012) DEM simulation of oblique shocks in gravity-driven granular flows with wedge obstacles. Granular Matter (doi:10.1007/s10035-012-0371-g)

[5] Cui P, Zeng C and Lei Yu (2015) Experimental analysis on the impact force of viscous debris flow. Earth Surf. Process. Landforms, 40, 1644-1655 (doi: 10.1002/esp.3744)

[6] Erdbrink CD (2014) Modelling Flow-Induced Vibrations of Gates in Hydraulic Structures. PhD Thesis, Computational Science, University of Amsterdam

[7] Faug T, Chanut B, Beguin R, Naaim M, Thibert E and Baraudi D (2010) A simple analytical model for pressure on obstacles induced by snow avalanches. Annals of Glaciology, 51(54), 1-8

[8] Faug T, Gauer P, Lied K and Naaim M (2008) About observations of the overrun length of avalanches overtopping catching dams: Cross-comparison of small scale laboratory experiments and observations from full-scale avalanches. Journal of Geophysical Research Atmospheres, 113(F3) (doi: 10.1029/2007JF000854)

[9] Fernandez-Nieto ED, Bouchut F, Bresch D, Castro Daz MJ and Mangeney A (2008) A new SavageHutter type model for submarine avalanches and generated tsunami. J. Comput. Phys., 227(16), 77207754

[10] Gray JMNT, Tai Y-C, and Noella S (2003) Shock waves, dead zones and particle-free regions in rapid granular free-surface flows. J. Fluid Mech., 491, 161-181 (doi: 10.1017/S0022112003005317)

[11] Hubl J, Strauss A, Holub M, Suda J (2005) Structural mitigation measures. Proceeding of $3^{\text {rd }}$ Probabilistic Workshop: Technical System + Natural Hazards

[12] Hungr O, Morgan GC and Lellerhals R (1984) Qualitative analysis of debris torrent hazards for design of remedial measures. Canedian Geotechnical Journal, 21(4), 663-677 
Journal of Nepal Mathematical Society (JNMS), Vol. 1, Issue 2 (2018); P. Kattel, B. M. Tuladhar

[13] Hungr O, Morgan GC, Vandine DF and Lister DR (1987) Debris flow defences in British Columbia. In Debris Flows/Avalanches: Process, Recognition, and Mitigation. Reviews in Engineering Geology, 7, 201-222

[14] Hutter K, Svendsen B and Rickenmann D (1996) Debris flow modelling review. Continuum Mech. Thermo. Dyn., 8, 1-35

[15] Iverson RM (1997) The physics of debris flows. Rev. Geophys., 35(3), 245-296

[16] Iverson RM and Denlinger RP (2001) Flow of variably fluidized granular masses across threedimensional terrain: 1. Coulomb mixture theory. J. Geophys. Res., 106(B1), 537-552

[17] Jiang GS and Tadmor E (1998) Non-oscillatory central schemes for multi-dimensional hyperbolic conservation laws. SIAM, J. Sci. Comput., 19, 1892-1917

[18] Johannesson T, Gauer P, Issler D and Lied K (2009) The design of avalanche protection dams. Recent practical and theoretical developments. European Commission. Directorate General for Research (Barbolini M, Domaas U, Harbitz CB, Johannesson T, Gauer P, Issler D, Lied K, Faug T, Naaim M).

[19] Johnson AM (1965) A Model for Debris Flow. PhD Thesis, Pansilvania State University, State College

[20] Kafle J, Pokhrel PR, Khattri KB, Kattel P, Tuladhar BM and Pudasaini SP (2016) Submarine landslide and particle transport in mountain lakes, reservoirs and hydraulic plants. Annals of Glaciology, 57(71), 232-244 (doi: 10.3189/2016AoG71A034)

[21] Kattel P (2014) Dynamics of Quasi-Three-Dimensional and Two-Phase Mass Flows. M. Phil. Dissertation, Kathmandu University, School of Science, Dhulikhel, Nepal

[22] Kattel P, Kafle J, Fischer J-T, Megili M, Tuladhar BM, Pudasaini SP (2018) Interaction of two-phase debris flow with obstacles. Engineering Geology, 242, 197-242 (doi: 10.1016/j.enggeo.2018.05.023)

[23] Kattel P, Khattri KB, Pokhrel PR, Kafle J, Tuladhar BM and Pudasaini SP (2016) Simulating glacial lake outburst floods with a two-phase mass flow model. Annals of Glaciology, 57(71), 349-358 (doi: 10.3189/2016AoG71A039)

[24] Mergili M, Fischer J-T, Krenn J and Pudasaini SP (2017) r.avaflow v1, an advanced open-source computational framework for the propagation and interaction of two-phase mass flow. Geosci. Model Dev., 10, 553-569 (doi:10.5194/gmd-10-553-2017)

[25] Nessyahu H and Tadmor E (1990) Non-oscillatory central differencing for hyperbolic conservation laws. J. Comput. Phys., 87(2), 408-463

[26] Li P, Li T, Lu Z, Li J (2017) Study on dynamic response of novel masonry structures impacted by debris flow. Sustainability, 9, 1-22 (doi:10.3390/su9071122)

[27] Pitman EB and Le L (2005) A two fluid model for avalanche and debris flows. Phil. Trans. R. Soc. A, 363(3), 1573-1601

[28] Piton G and Recking A (2016) Design of sediment traps with open check dams. I: Hydraulic and deposition Processes. Journal of Hydraulic Engineering (doi: 10.1061/(ASCE)HY.1943-7900.0001048)

[29] Pudasaini SP (2012) A general two-phase debris flow model. J. Geophysics. Res., 117. F03010 (doi: 10.1029/2011JF002186)

[30] Pudasaini SP (2014) Dynamics of submarine debris flow and tsunami. Acta Mechanica, 225, 2423-2434 (doi: 10.1007/s00707-014-1126-0)

[31] Pudasaini SP and Hutter K (2007) Avalanche Dynamics: Dynamics of Rapid Flows of Dense Granular Avalanches, Springer, Berlin, New York 
[32] Pudasaini SP and Krautblatter M (2014) A two-phase mechanical model for rock-ice avalanches. J. Geophys. Res. Earth Surf., 119(10), 2272-2290 (doi:10.1002/2014JF003183)

[33] Pudasaini SP and Fischer J-T (2016) A mechanical model for phase-separation in debris flow. arXiv:1610.03649v1

[34] Pudasaini SP, Wang Y and Hutter K (2005) Modelling debris flows down general channels. Nat. Hazards Earth Syst. Sci., 5, 799-819

[35] Tai Y-C, Gray JMNT, Hutter K and Noelle S (2001) Flow of dense avalanches past obstructions. Annals of Glaciology, 32, 281-284

[36] Tai Y-C, Noella S, Gray JMNT and Hutter K (2002) Shock-capturing and front tracking methods for granular avalanches. J. Comput. Phys., 175(1), 269-301

[37] Takahashi T (1991) Debris Flow. IAHR-AIRH Monograph Series A, Balkema, Rotterdam, Netherlands

[38] Takahashi T (2007) Debris Flow: Mechanics, Prediction and Countermeasures. Taylor and Francis, New York

[39] Teufelsbauer H, Wang Y, Chiou MC and Wu W (2009) Flow-obstacle-interaction in rapid granular avalanches: DEM simulation and comparison with experiment. Granular Matter, 11(4), 209-220 (doi:10.1007/s10035-009-0142-6)

[40] Teufelsbauer H, Wang Y, Pudasaini SP, Borja RI and Wu W (2011) DEM simulation of impact force exerted by granular flow on rigid structures. Acta Geotechnica (doi: 10.1007/s11440-011-0140-9)

[41] VanDine DF (1996) Debris flow control structures for forest engineering. Res. Br., B.C. Min. For., Victoria, B.C., Work. Pap. 08/1996

[42] Wawra M (2010) Numerical Modelling of Snow Avalanches: Interaction Between Granular Flow and Obstruction, PhD Thesis, University of Soil Culture, Vienna

[43] Wendeler C (2016) Debris-Flow Protection System for Mountain Torrents-Basic Principles for Planning and Calculation of Flexible Barriers. WSL Ber., 44, 279pp, ISSN 2296-3456

[44] Xie T, Yang H, Wei F, Gardner JS, Dai Z and Xie X (2014) A new water-sediment separation structure for debris flow defence and its model test. Bull. Eng. Geol. Environ., 73, 947-958 (doi: 10.1007/s10064014-0585-9) 